\title{
Subcutaneous fat metastasis at presentation in cervical cancer: case report and review of the literature
}

\author{
Georgia Zachou ${ }^{1}$, James Dilley ${ }^{1}$, Ayshea Hameeduddin ${ }^{1}$, Millie Light ${ }^{1}$, and Saurabh \\ Phadnis $^{1}$ \\ ${ }^{1}$ Barts Health NHS Trust
}

November 30, 2020

\begin{abstract}
Subcutaneous metastases at presentation in cervical cancer are rare and they are associated with ominous prognosis. In this literature review, we present a case of skin metastasis and systematically review the current literature with the aim to discuss trends, treatment and survival of the reported cases.
\end{abstract}

